\title{
Analysis of natural aroma and flavor of MD2 pineapple variety (Ananas comosus [L.] Merr.)
}

\author{
Lukáš Žemlička ${ }^{\mathrm{a}}$, Peter Fodran ${ }^{\mathrm{b}}$, Emil Kolek ${ }^{\mathrm{c}}$, Nadežda Prónayovád \\ ${ }^{a}$ Department of Nutrition and Food Assessment, Faculty of Chemical and Food Technology, \\ Slovak University of Technology, Radlinského 9, SK-812 37 Bratislava, Slovakia \\ ${ }^{b}$ FLOP, Mandlová 37, SK-851 10 Bratislava, Slovakia \\ 'VÚP Food Research Institute, Priemyselná 4, SK-824 75 Bratislava, Slovakia \\ ${ }^{d}$ Department of NMR Spectroscopy and Mass Spectroscopy, Faculty of Chemical and Food Technology, \\ Slovak University of Technology, Radlinského 9, SK-812 37 Bratislava, Slovakia
}

lukas.zemlicka@stuba.sk

\begin{abstract}
Aroma and flavor profile of MD2 pineapple variety was investigated. Fruits imported from different geographical regions (Costa Rica, Puerto Rico) were labeled as an organic food. Characteristic volatile and non-volatile compounds obtained by hydro-distillation and direct percolation were identified and quantified by gas chromatography-mass spectroscopy (GC/MS). At least 22 components in percolated extract (or 17 in distillate) were detected according to their mass spectra and retention time. Relative concentration of identified substances varied from 547.7 to $1110.0 \mu \mathrm{g} \cdot \mathrm{kg}^{-1}$. Analysis showed dominance of esters and furanone-derived compounds as major aroma constituents. Most abundant volatiles identified in all samples were methyl 2-methylbutanoate and methyl hexanoate. Relationships between volatile and non-volatile compounds were also studied.
\end{abstract}

Keywords: pineapple, MD2 variety, flavor, natural aroma, GC/MS

\section{Introduction}

Pineapple (Ananas comosus [L.] Merr.) is a very well known fruit all over the world and it represents one of the largest commodities among tropical fruits imported to Europe. There are many cultivars, with varied colors, shapes, sizes, odor, and flavors. Among them, MD2 (or Gold) cultivar has stood out in the international markets because of its sensory characteristics, highlighting flavor, sweetness to acidity balance, and juiciness. The flavor of pineapple is a blend of a number of volatile and non-volatile compounds that are present in small amounts and in complex mixtures, with the non-volatile compounds more difficult to analyze (Pickenhagen 1999). In fact, the perception of sweetness can be modified by the acid content and aroma compounds (Baldwin 2004). Nowadays, flavor quality is being addressed as key element for consumer acceptance.

The pineapple aroma also attracts a considerable attention due to unusual sensory properties. As one of the few commercially produced fruit flavor is non-identical to its natural counterpart. Although the allyl esters are widely used as prevailing sensory ingredients an exact composition of the core contributors is still not known in detail. The presence of allyl esters in natural pineapple aroma was already described (Nitz and Drawert 1982), however, their verification is disputable especially in the case if they were isolated only by hydro-distillation (Näf-Müller and Willhalm 1971). The process of distillation of plant material involves hydrolysis and thermal decomposition. Moreover, steam distillation is a relatively rough method and this treatment itself could lead to destruction of thermo-labile substances. It was confirmed that such a product possesses neither quality nor sensory properties of fresh pineapple fruit but is more similar to aroma of green apples and ripe pears.

In the studies mentioned above, esters of 3-(methylthio) propionic acid, esters of hydroxy and/or acetoxy acids, furane derivates and lactones were found as prevalent compounds of pineapple fruit aromas. Many of these compounds have been identified and reported by several authors from fresh fruits, processed pineapple products and pineapple essences (Umano et al. 1992, Elss et al. 2005). A rather rare is the study carried out by Brat et al. (2004) where the terpene hydrocarbons have been found as the main components of the natural pineapple aroma. Recent data (Preston et al. 2003, Tokimoto et al. 2005) are referring to gas chromatography analysis on capillary columns with several types of embedded films of different polarity.

The occurrence of MD2 pineapple cultivar is increasing on European market but only limited information is available about its flavor and aroma 
profile. In the present study, our investigation was focused on volatile and non-volatile constituents of samples and on the way, how they are affected by different processing conditions.

\section{Experimental}

\section{Materials and methods}

\section{Chemicals}

All chemicals and reagents used were of analytical grade. Reference material was prepared in our laboratory by standard procedures of organic synthesis.

\section{Sample preparation}

The MD2 variety of pineapple, labeled as organic food, was chosen and bought at local stores. Selected fruits were in good condition and free from mechanical injuries or other defects, insects and pathogens, and were processed as follows:

\section{Hydrodistillation}

Fruit $(2.8 \mathrm{~kg})$ was sliced to cubes without peeling and submerged into adequate amount of preheated $\left(30^{\circ} \mathrm{C}\right)$ de-mineralized water $(1: 3, \mathrm{w} / \mathrm{v})$. The volume of $1000 \mathrm{ml}$ of distillate was obtained from the fruit during distillation process. Original ratio of water to fruit has been kept all the time. A cooled distillate was extracted three times with dichloromethane (Mikrochem, Pezinok, Slovakia), the extract was dried by anhydrous sodium sulfate (Mikrochem, Pezinok, Slovakia) and the solvent was carefully distilled off by using rectification column at the final volume of $5 \mathrm{ml}$. Natural pineapple aroma prepared in such a way was analyzed by GC/MS method.

\section{Percolation}

The same quantity of unpeeled and sliced fruit was percolated twice with $3000 \mathrm{ml}$ of diethyl ether (Mikrochem, Pezinok, Slovakia) and then twice with $3000 \mathrm{ml}$ of dichloromethane. Each cycle lasted for 2 hours. The percolate was desiccated with anhydrous $\mathrm{Na}_{2} \mathrm{SO}_{4}$ and the solvent was concentrated by using an efficient rectification column at the volume of $50 \mathrm{ml}$. In order to remove all residual solvents from the mixture, the distillation process has continued after adding $10 \mathrm{ml}$ of refined ethanol (Mikrochem, Pezinok, Slovakia) in such a manner that the temperature of the still head did not exceed $45{ }^{\circ} \mathrm{C}(101.3 \mathrm{kPa})$. Afterward, the distillation residue was frozen at $-8^{\circ} \mathrm{C}$ and the precipitated wax fractions were filtered. Natural pineapple aroma prepared by this means was analyzed by GC/MS method.

\section{GC analysis}

An Agilent Technologies 6890 (Agilent Technologies, Palo Alto, USA) gas chromatograph equipped with an Agilent Technologies 5973 inert mass selective detector (MSD) was used for the determination of volatiles in samples. The volatiles were separated on different non-polar columns HP-5MS, $30 \mathrm{~m} \times 0.25 \mathrm{~mm} \times 0.25 \mu \mathrm{m}(19091 \mathrm{~S}-433)$ and Ultra 1, $50 \mathrm{~m} \times 0.32 \mathrm{~mm} \times 0.52 \mu \mathrm{m}(19091 \mathrm{~A}-115)$; and on polar column DB-FFAP, $30 \mathrm{~m} \times 0.25 \mathrm{~mm}$ $\times 0.25 \mu \mathrm{m}$ (122-3232). Split mode (30:1) was used in all experiments. The carrier gas was helium and the injector temperature was $250^{\circ} \mathrm{C}$. The oven temperature for HP5-MS and Ultra 1 was programmed as isothermal at $60{ }^{\circ} \mathrm{C}$ for 1 minute then heated to $320^{\circ} \mathrm{C}$ at a rate of $5^{\circ} \mathrm{C} \cdot \mathrm{min}^{-1}$. The temperature program for DB-FFAP was isothermal at $50{ }^{\circ} \mathrm{C}$ for 1 minute and then ramped to $230{ }^{\circ} \mathrm{C}$ at a rate of $5{ }^{\circ} \mathrm{C} \cdot \mathrm{min}^{-1}$. Mass spectra were obtained by electron ionization (EI) at $70 \mathrm{eV}$. The mass-to-charge $(\mathrm{m} / \mathrm{z})$ ratio was monitored in the range of 29-400 Dalton with an acquisition rate $1.16 \mathrm{~Hz}$. Identification was carried out by comparison of the mass spectra and chromatographic data of the target compounds with reference materials and NIST02 library. The relative quantification was performed by using ethyl 3-hydroxybutanoate as external standard.

\section{Synthesis of reference material}

For the purpose of content analysis some selected substances of natural pineapple aroma have been synthesized. The following standards were prepared by common procedures of organic synthesis (Becker 1971): ethyl 3-oxobutanoate by reduction of ethyl acetoacetate (Lachema, Brno, Czech Republic) with sodium borohydride (Merck, Darmstadt, Germany), ethyl 3-oxohexanoate by acylation of magnesium salt of ethyl acetoacetate with butyryl chloride (Sigma-Aldrich, Steinheim, Germany). The acylated intermediate was transformed by ester cleavage and the product was reduced with $\mathrm{NaBH}_{4}$ to corresponding oxo derivative. The N-acetyl-pyridinium chloride has been used for re-esterification of oxo esters to acetoxy esters. This procedure was done as follows: $0.1 \mathrm{~mol}$ of oxo ester and $0.11 \mathrm{~mol}$ of freshly redistilled anhydrous pyridine (Lachema, Brno, Czech Republic) were dissolved in $200 \mathrm{ml}$ of dry dichloromethane. After that $0.105 \mathrm{~mol}$ of acetyl chloride (Merck, Darmstadt, Germany), dispersed in $100 \mathrm{ml}$ of dry dichloromethane was slowly added drop-wise with vigorous stirring and cooling. The whole mixture was stirred at ambient temperature for 30 minutes and then 2 hours under reflux. When the solution has reached laboratory temperature, precipitated pyridinium hydrochloride was filtered and washed with $200 \mathrm{ml}$ of dry dichloromethane. 
Filtrate was washed with dilute hydrochloric acid (Lachema, Brno, Czech Republic) and cold water; then washed with diluted solution of sodium bicarbonate (Mikrochem, Pezinok, Slovakia) and cold water. The purified solution was dried with anhydrous $\mathrm{Na}_{2} \mathrm{SO}_{4}$ and dichloromethane was distilled off. Final product was redistilled on a short Vigreux column.

\section{Results and discussion}

\section{Flavor components of natural pineapple aroma}

In this study the natural pineapple aroma of MD2 variety was investigated. The samples were labeled as organic product and came from different farmers. The data confirm an extremely high efficiency of sensory components which are involved in the pineapple aroma. The overall yield of aroma compounds (Table 1) based on the fresh unpeeled fruit was comparable to others (Näf-Müller and Willhalm 1971, Umano et al. 1992).

Tab. 1. Yield of the pineapple aroma compounds.

\begin{tabular}{lcc}
\hline Producer & Method of Isolation & Yield [\%] \\
\hline \multirow{2}{*}{ Costa Rica } & Distillation & 0.0006 \\
& Percolation & 0.0009 \\
Puerto Rico & Distillation & 0.0008 \\
& Percolation & 0.0013 \\
\hline
\end{tabular}

$\mathrm{a}-\%$ of aroma compounds per fresh pineapple mass.

The mutual comparison of aroma constituents (Table 2), within each class of compounds and each method of isolation, did not produce a significant discrepancy. Quantitatively, however, the isolation methods used in this study showed an extremely wide range of variations in the relative amounts of aroma compounds. Relative concentration of identified substances varied from 547.7 to $1110.0 \mu \mathrm{g} . \mathrm{kg}^{-1}$. The total number of identified components acquired by hydro-distillation was reduced in the case of using HP-5MS and DB-FFAP column, e.g. the structure of distillate separated by HP-5MS column was very simple and no substances were found above the detection limit after 10th minute. Esters of long-chain fatty acids and free fatty acids have been obtained in lower yield; on the contrary, the increase of esters of medium and short-chain fatty acids was noticeable. The most abundant volatiles identified in distillate were methyl 2-methyl butanoate and methyl hexanoate. In this case, the increase was higher by one order of magnitude in comparison to percolated extract. Esters were the major components which accounted more than $63 \%$ of total distilled aroma for Puerto Rico and 40 \% for Costa Rica. Presence of aforementioned esters together with methyl 3-(methylthio)-propanoate and furanone-derived compounds have participated on the distinctive flavor of pineapple in all examined fruits.

Similar results were observed also by other authors with different varieties of pineapple (Umano et al. 1992, Preston et al. 2003, Tokimoto et al. 2005). In addition, esters were the major constituents also in percolated extracts while more characteristic substances as lactones, aldehydes and terpenes have appeared only in minor amounts or were lacking completely. Overall sensation, however, also depends on the presence of small quantities of other volatiles, either with low threshold value or with the flavor-enhancing properties. The latter may include dispersed droplets of mid- to long-chain fatty acids and free fatty acids that play a role in the intensification of in-mouth sensory perception (Engelen and de Wijk 2012).

Thermal processes are considered as a factor contributing to overall change in volatile composition. According Elss et al. (2005) is furfural formed mainly as a product of thermal action and could be determined by range of the Maillard reaction. In present study, however, pineapple from Puerto Rico contained furfural not only in distillate but also in percolate and thus their statement cannot be confirmed.

It is known that some specific compounds are associated with ripening. Increase in volatiles concentration can be explained by changes occurring during maturation. It begins several weeks before harvest when volatile compounds are synthesized from free amino acids, carbohydrates, and through $\beta$-oxidation of fatty acids (Cadwallader 2005). As volatile compound composition changed throughout the different stages of maturity; ripe pineapple had larger contents of most of the volatile compounds as compared with green and very green fruits. Due to a long period of shipping we cannot evaluate changes during individual stages of ripening, although the content of esters in the fruit imported from Puerto Rico is increasing.

Some fundamental differences might be seen when comparing our data with results of other authors. Since the interpretation of mass spectra has not been conclusive, the appropriate standards were synthesized. Material was chromatographically purified (> $98 \%$ ) and each compound has been verified by NMR. Subsequently, all the standards were confronted with the data of 3-hydroxy and 3-acetoxy esters which were obtained from natural flavor complex. Further conclusions were drawn on the basis of retention times and spectral fragmentation, and according analysis they can be regarded as identical compounds. However, the comparison of mass spectrum of ethyl 3-hydroxybutanoate pre- 
Tab. 2. Relative concentration of aroma compounds in fresh pineapple obtained by GC/MS under different analysis conditions.

\begin{tabular}{|c|c|c|c|c|c|c|}
\hline \multirow[b]{2}{*}{ Class } & \multirow[b]{2}{*}{ Compound } & \multicolumn{5}{|c|}{ Relative concentration $\left[\mu \mathrm{g} . \mathrm{kg}^{-1}\right]$} \\
\hline & & $\begin{array}{c}\text { Extract } \\
\text { Puerto } \\
\text { Rico }^{\text {b }}\end{array}$ & $\begin{array}{c}\text { Extract } \\
\text { Costa } \\
\text { Rica }^{c}\end{array}$ & $\begin{array}{c}\text { Distillate } \\
\text { Puerto } \\
\text { Rico }^{\mathrm{d}}\end{array}$ & $\begin{array}{c}\text { Distillate } \\
\text { Costa } \\
\text { Rica }^{\mathrm{e}}\end{array}$ & $\begin{array}{c}\text { Distillate } \\
\text { Puerto } \\
\text { Rico U1 }{ }^{\mathrm{f}}\end{array}$ \\
\hline \multirow[t]{35}{*}{ Esters } & 2-Methylpropyl formate & - & - & - & - & 7.2 \\
\hline & Methyl acetate & - & 4.3 & - & - & - \\
\hline & Ethyl acetate & - & - & - & - & 2.9 \\
\hline & Hexyl acetate & - & 4.6 & - & - & - \\
\hline & Methyl propanoate & - & 8.2 & - & - & 6.5 \\
\hline & Methyl 3-(methylthio)-propanoate & 72.2 & 37.0 & 17.9 & 34.6 & 110.4 \\
\hline & Methyl 2-methylpropanoate & - & - & - & - & 43.5 \\
\hline & Methyl 2-hydroxy-2-methylpropanoate & - & - & - & - & 1.1 \\
\hline & Methyl butanoate & - & - & - & - & 70.0 \\
\hline & Methyl 2-methylbutanoate & 208.0 & 253.3 & 44.8 & 31.7 & 38.7 \\
\hline & Methyl 3-hydroxybutanoate & 24.8 & 5.8 & 30.9 & 9.7 & - \\
\hline & Methyl 3-acetoxybutanoate & - & - & - & 141.1 & - \\
\hline & Methyl 2-hydroxy-2-methylbutanoate & 43.2 & - & 45.4 & - & 30.0 \\
\hline & Methyl 3-hydroxy-2-methylbutanoate & 40.4 & - & 36.3 & - & 14.1 \\
\hline & Methyl 2-methyl-3-oxobutanoate & 2,11 & - & - & - & 7.4 \\
\hline & Ethyl 2-methylbutanoate & - & - & - & - & 2.2 \\
\hline & (Z)-hex-3-enyl 2-methylbutanoate & - & - & - & - & 1.7 \\
\hline & Methyl pentanoate & - & - & - & - & 4.8 \\
\hline & Methyl 2-methylpentanoate & - & - & 2.2 & - & - \\
\hline & Methyl 2,4-dimethylpentanoate & - & 5.8 & - & 5.4 & - \\
\hline & Ethyl 3-methylpentanoate & 1.1 & - & - & - & - \\
\hline & Methyl hexanoate & 152.9 & 132.1 & 89.2 & 27.0 & 32.4 \\
\hline & Methyl 3-hydroxyhexanoate & 32.0 & - & 29.1 & - & 9.3 \\
\hline & Methyl 3-acetoxyhexanoate & 30.2 & - & 42.7 & 15.1 & 11.5 \\
\hline & Methyl 5-acetoxyhexanoate & 98.3 & - & 97.9 & - & 30.8 \\
\hline & Ethyl hexanoate & - & - & 27.1 & - & 7.9 \\
\hline & Methyl heptanoate & - & - & - & - & 7.4 \\
\hline & Methyl octanoate & 33.8 & - & 34.3 & - & 23.9 \\
\hline & Methyl (Z)-oct-4-enoate & - & - & - & - & 6.7 \\
\hline & Methyl (Z)-dec-4-enoate & - & - & - & - & 4.8 \\
\hline & Ethyl octadec-9-enoate & 21.5 & - & - & - & - \\
\hline & Dimethyl malonate & - & 113.4 & - & 23.0 & 14.6 \\
\hline & Dimethyl succinate & - & - & - & - & 3.8 \\
\hline & Dimethyl glutarate & - & - & - & - & 1.5 \\
\hline & Dimethyl adipate & - & - & - & - & 0.6 \\
\hline Total & & 760.4 & 564.4 & 497.8 & 287.7 & 495.4 \\
\hline \multirow[t]{8}{*}{ Aldehydes } & Furfural & 47.3 & - & 97.6 & - & 69.1 \\
\hline & Furfural diethyl acetal & - & - & 7.5 & - & - \\
\hline & (E)-3,7-Dimethylocta-2,6-dienal & - & 0.8 & - & - & - \\
\hline & Vanillin & - & 10.7 & - & - & - \\
\hline & Acetaldehyde diethylacetal & - & 3.1 & - & - & - \\
\hline & Hexanal diethylacetal & - & 0.5 & - & - & - \\
\hline & 2-Methyl butanal & - & - & - & - & 1.8 \\
\hline & 3-Methyl butanal & - & - & - & - & 1.9 \\
\hline
\end{tabular}


Tab. 2. (continue) Relative concentration of aroma compounds in fresh pineapple obtained by GC/MS under different analysis conditions.

\begin{tabular}{|c|c|c|c|c|c|c|}
\hline \multirow[b]{2}{*}{ Class } & \multirow[b]{2}{*}{ Compound } & \multicolumn{5}{|c|}{ Relative concentration $\left[\mu \mathrm{g} \cdot \mathrm{kg}^{-1}\right]$} \\
\hline & & $\begin{array}{c}\text { Extract } \\
\text { Puerto } \\
\text { Rico }^{\mathrm{b}}\end{array}$ & $\begin{array}{c}\text { Extract } \\
\text { Costa } \\
\text { Rica }^{c}\end{array}$ & $\begin{array}{c}\text { Distillate } \\
\text { Puerto } \\
\text { Rico }^{\mathrm{d}}\end{array}$ & $\begin{array}{c}\text { Distillate } \\
\text { Costa } \\
\text { Rica }^{\mathrm{e}}\end{array}$ & $\begin{array}{c}\text { Distillate } \\
\text { Puerto } \\
\text { Rico U } 1^{\mathrm{f}}\end{array}$ \\
\hline \multirow[t]{3}{*}{ Aldehydes } & 3-Methylbut-2-enal & - & - & 2.4 & - & - \\
\hline & 2-Methylpent-2-enal & - & - & - & - & 6.5 \\
\hline & 2-Phenylacetaldehyde & - & - & - & - & 8.1 \\
\hline Total & & 47.3 & 15.0 & 107.5 & - & 87.3 \\
\hline \multirow[t]{4}{*}{ Ketones } & 2,5-Dimethyl-4-methoxy-3(2H)furanone & 39.7 & 48.6 & 43.4 & 47.6 & - \\
\hline & 5-ethyl-4-hydroxy-2-methyl-3(2H)furanone & - & - & - & - & 19.1 \\
\hline & 2-Butanone & - & - & - & - & 28.7 \\
\hline & 2-Methyl-3-butanone & - & - & - & - & 54.7 \\
\hline Total & & 39.7 & 48.6 & 43.4 & 47.6 & 102.4 \\
\hline \multirow[t]{2}{*}{ Lactones } & $\gamma$-Hexalactone & 25.3 & - & 8.3 & - & 16.2 \\
\hline & $\gamma$-Octalactone & - & 14.7 & - & 19.9 & - \\
\hline Total & & 25.3 & 14.7 & 8.3 & 19.9 & 16.2 \\
\hline \multirow[t]{5}{*}{ Alcohols } & 3-Penten-2-ol & - & 9.6 & - & 8.9 & - \\
\hline & 2-Methylbutan-2-ol & - & - & - & - & 5.3 \\
\hline & 4-Methylpent-3-en-1-ol & - & - & - & - & 4.1 \\
\hline & 2-Methylbut-3-en-2-ol & - & - & - & - & 6.9 \\
\hline & Hexadecan-1-ol & - & - & - & - & 3.4 \\
\hline Total & & - & 9.6 & - & 8.9 & 19.6 \\
\hline \multirow[t]{2}{*}{ Terpenes } & Limonene & 85.9 & - & - & - & - \\
\hline & Squalene & - & 1.2 & - & - & - \\
\hline Total & & 85.9 & 1.2 & - & - & - \\
\hline \multirow[t]{4}{*}{ Acids } & Hexanoic acid & - & - & 38.0 & - & 9.1 \\
\hline & Hexadecanoic acid & 45.1 & 40.1 & - & 69.4 & 52.1 \\
\hline & Octadecanoic acid & 51.8 & 31.9 & - & 33.9 & - \\
\hline & Octadec-9-enoic acid & 45.1 & 39.6 & - & 75.4 & 47.8 \\
\hline Total & & 142.0 & 111.6 & 38.0 & 178.7 & 109.0 \\
\hline \multirow[t]{5}{*}{ Hydrocarbons } & Undecane & - & 1.9 & 2.7 & 1.5 & - \\
\hline & Dodecane & 4.9 & - & 3.3 & - & - \\
\hline & Tridecane & 4.6 & 1.9 & 2.3 & 2.0 & - \\
\hline & Hexadecane & - & 1.4 & - & 1.5 & - \\
\hline & Hexadec-1-ene & - & - & - & - & 2.4 \\
\hline Total & & 9.5 & 5.3 & 8.2 & 4.9 & 2.4 \\
\hline \multirow[t]{3}{*}{ Miscellaneous } & S-Methyl methanethiosulfinate & - & - & - & - & 0.5 \\
\hline & 1,2,3-Trimethylbenzene & - & - & - & - & 1.7 \\
\hline & 1-Ethyl-2-methylbenzene & - & - & - & - & 0.5 \\
\hline Total & & - & - & - & - & 2.7 \\
\hline
\end{tabular}

- not detected, b - extract separated by HP-5MS capillary column, c - extract separated by DB-FFAP capillary column, d - distillate separated by HP-5MS capillary column, e - distillate separated by DB-FFAP capillary column, $\mathrm{f}$ - distillate separated by Ultra 1 capillary column.

sented in this study versus the spectrum declared by Umano at al. (1992) has brought a particular differences. The fragmentation pattern of ethyl 3-hydroxybutanoate acquired during our investigation was as follows: 43 (100), 45 (88), 117 (83),
88 (77), 87 (75), 71 (64), 60 (60), 42 (43), 29 (33), 89 (27), 61 (24), 70 (22), 85 (19), 69 (17), 41 (11); while Umano at al. (1992) stated 43 (100), 45 (52), 42 (37), 71 (22), 60 (22), 87 (17), 117 (13). The reason for this variation is unclear. 


\section{Other non-flavor components}

Many other substances unrelated to the flavor have been also detected throughout the experiment. Detection of aromatic hydrocarbons as toluene, ethylbenzene and $p$-xylene in pineapples from Costa Rica indicate the possibility of cross-contamination during handling, packaging and/or storage. Since the substances cannot be considered for the genuine fruit metabolites, they could be presented as a residue of printing inks and solvents.

Analysis of percolated fruit from Puerto Rico has proved presence of insecticide Carbaryl $\left(7.3 \mu \mathrm{g} \cdot \mathrm{kg}^{-1}\right)$ and fungicide Triadimenol $\left(2.7 \mu \mathrm{g} \cdot \mathrm{kg}^{-1}\right)$. As these contaminants are virtually non-volatile substances we did not find any traces of them in distillate. This assumption is supported by the presence of other chlorinated hydrocarbons, e.g. 2-chloro-2-methylbutane, 3-chloro-3-methylbut-1-ene, 1-chloro-2-methylbut-2-ene and 2,3-dichloro-2-methylbutane which have been found in fruit processed separately and identified by Ultra 1 capillary column. Occurrence of fungicide Triadimefon $\left(3.7 \mu \mathrm{g} \cdot \mathrm{kg}^{-1}\right)$ in fruit from Costa Rica was proved in percolate and in distillate as well. These findings have confirmed a violation of food safety standards for organic products in both cases.

The greatest hurdle for the import of organic produced ripe MD2 pineapple to Europe is not the poor visual quality of the fruit, which is usually affected by shipping time or inadequate storage facilities, but the specific marketing conditions. In January 2009 new EU regulations went into effect for the production, control and labeling of organic products. According to the legal framework (EU Council Regulation No. 834/2007) the distribution of organic products from third countries is only permitted on the common market, when they are produced and controlled under the same or equivalent conditions. However, the import regime has been expanded although it seems that control bodies are not able to carry out any relevant inspections in situ.

\section{Conclusions}

Up to date, nearly 300 different components had been recognized in pineapple flavor (Umano et al. 1992, Brat et al. 2004, Elss et al. 2005, Tokimoto et al. 2005) however, only some of them have been identified as a key contributors of the pineapple aroma. The aroma profile of inspected MD2 variety consisted mainly from esters what represented $63 \%$ (Puerto Rico) or 40 \% (Costa Rica) of total extracted substances. Methyl 2-methyl butanoate and methyl hexanoate were the most abundant volatiles identified in distillate. As these fruits were labeled as an organic product the presence of pesticide has indicated a violation of food safety standards.

Any deeper comparison of our results with those which have been reported on this topic is difficult. The reason is an enormous variability of raw material, differences in origin, cultivated variety, maturity, storage period and other pre- and post-harvest parameters which must be taken into account. All these factors may affect quality and quantity of components which create a complex of the natural pineapple aroma.

\section{References}

Baldwin EA (2004) Flavor In: Gross K, Wang YC, Saltveit M (Eds.) The commercial storage of fruits, vegetables and florist and nursery stocks, Agriculture Handbook Nr 66. Beltsville: USDA-ARS.

Becker H (1971) Organic synthesis: Organikum. Praha: Academia.

Brat P, Hoang LN, Soler A, Reynes M, Brillouet JM (2004) Journal of Agricultural and Food Chemistry 52: $6170-6177$.

Cadwallader KR (2005) Flavor and volatile metabolism in produce In: Lamikanra O, Imam SH, Ukuku DO (Eds.) Produce degradation: pathways and prevention. Boca Raton: CRC Press.

Engelen L and de Wijk RA (2012) Oral Processing and Texture Perception. In: Chen J, Engelen L (Eds.) Food Oral Processing: Fundamentals of Eating and Sensory Perception. Oxford, UK: Wiley-Blackwell.

Elss S, Preston C, Hertzig C, Heckel F, Richling E, Schreier P (2005) LWT-Food Science and Technology 38: 263-274.

European Union: Council of the European Union, Council Regulation (EC) No. 834/2007 of 28 June 2007 on organic production and labelling of organic products and repealing Regulation (EEC) No. 2092/91, [online]. Brussels: European Commission, DG Agriculture and Rural Development, 28 June 2007, [cit. 14 November 2012]. <http://ec.europa.eu/ agriculture/organic/eu-policy/legislation_en>

Näf-Müller R, Willhalm B (1971) Helvetica Chimica Acta 54: $1880-1890$

Nitz S, Drawert F (1982) Chemie, Mikrobiologie, Technologie der Lebensmittel 7: 148-149.

Pickenhagen W (1999) Flavor chemistry: Thirty Years of Progress. New York: Kluwer Academic.

Preston C, Richling E, Elss S, Appel M, Heckel F, Hartlieb A, Schreier P (2003) Journal of Agricultural and Food Chemistry 51: 8027-8031.

Tokimoto Y, Steinhaus M, Buttner A Schieberle P (2005) Bioscience Biotechnology Biochemistry 69: 1323-1330.

Umano K, Hagi Y, Nakahara K, Shoji A, Shibamoto T (1992) Journal of Agricultural and Food Chemistry 40: 599-603. 